\title{
Molecular typing of Trichomonas vaginalis isolates by actin gene sequence analysis and carriage of $T$. vaginalis viruses
}

\author{
Simon C. Masha ${ }^{1,2,3^{*}}$, Piet Cools ${ }^{2}$, Tania Crucitti ${ }^{4}$, Eduard J. Sanders ${ }^{1}$ and Mario Vaneechoutte ${ }^{2}$
}

\begin{abstract}
Background: The protozoan parasite Trichomonas vaginalis is the most common non-viral, sexually transmitted pathogen. Although T. vaginalis is highly prevalent among women in Kenya, there is lack of data regarding genetic diversity of isolates currently in circulation in Kenya.

Methods: Typing was performed on 22 clinical isolates of T. vaginalis collected from women attending the antenatal care clinic at Kilifi County Hospital, Kenya, in 2015. Genotyping followed a previously proposed restriction fragment length polymorphism (RFLP) scheme, which involved in silico cleavage of the amplified actin gene by Hindll, Msel and Rsal restriction enzymes. Phylogenetic analysis of all the sequences was performed to confirm the results obtained by RFLP-analysis and to assess the diversity within the RFLP genotypes. Additionally, we determined carriage of the four different types of Trichomonas vaginalis viruses (TWs) by polymerase chain reaction.
\end{abstract}

Results: In silico RFLP-analysis revealed five actin genotypes; $50.0 \%$ of the isolates were of actin genotype E, 27.3\% of actin genotype $\mathrm{N}, 13.6 \%$ of actin genotype $\mathrm{G}$ and $4.5 \%$ of actin genotypes I and P. Phylogenetic analysis was in agreement with the RFLP-analysis, with the different actin genotypes clustering together. Prevalence of TWs was 43.5\% (95\% confidence interval, Cl: 23.2-65.5). TW1 was the most prevalent, present in $39.1 \%$ of the strains and $90 \%$ of the T. vaginalis isolates which harbored TWs had more than one type of TV. None of the isolates of actin genotype E harbored any TW.

Conclusion: The presence of five actin genotypes in our study suggests notable diversity among T. vaginalis isolates occurring among pregnant women in Kilifi, Kenya. Isolates of the most prevalent actin genotype $\mathrm{E}$ lacked TVs. We found no association between T. vaginalis genotype, carriage of TWs and symptoms. Further studies with higher number of strains should be conducted in order to corroborate these results.

Keywords: Trichomonas vaginalis, Trichomonas vaginalis viruses, actin gene, Typing, Kilifi, Kenya

\section{Background}

Trichomonas vaginalis is a flagellated protozoan parasite that infects the human urogenital tract, causing the most common non-viral, sexually transmitted infectious disease worldwide [1]. The prevalence of T. vaginalis among women in sub-Saharan Africa is $11.5 \%$ [1]. In about half of the infected women, $T$. vaginalis causes a malodorous vaginal discharge, vulval irritation and

\footnotetext{
* Correspondence: schengo@kemri-wellcome.org

${ }^{1}$ Centre for Geographic Medicine Research - Coast, Kenya Medical Research Institute (KEMRI), P.O. Box 230-80108, Kilifi, Kenya

${ }^{2}$ Laboratory Bacteriology Research, Faculty of Medicine and Health Sciences, Ghent University, De Pintelaan, 1859000 Ghent, Belgium

Full list of author information is available at the end of the article
}

inflammation, and a 'strawberry cervix' characterized by punctate hemorrhagic lesions [2]. Men typically remain asymptomatic, but can suffer from urethral discharge, dysuria, urethritis, epididymitis and prostatitis $[2,3]$. Trichomonas vaginalis has been associated with adverse pregnancy outcomes, such as preterm birth and premature rupture of membranes [4-6], increased shedding and acquisition of the human immunodeficiency virus (HIV) $[7,8]$, hence contributing to the HIV pandemic.

The global prevalence of $T$. vaginalis and the health sequelae associated with it have necessitated the need to understand its genetic make-up. Trichomonas vaginalis is a complex pathogen, with a genome size of $~ 160$ megabases, 
two-thirds of which is composed of repeats and transposable elements [9]. Some strains of T. vaginalis can harbor up to four types of Trichomonas vaginalis viruses (TVVs) [10]. TVVs are members of the family Totiviridae under the distinct genus Trichomonasvirus [11]. Carriage of TVVs has been suggested to upregulate pro-inflammatory host responses [12] and T. vaginalis immunogenic protein P270 [13] and is also associated with differential qualitative and quantitative expression of cysteine proteinases [14]. Thus, since TVVs induce various phenotypic changes that may impact T. vaginalis virulence [14], determining carriage of TVVs seems to be essential in the characterization of $T$. vaginalis infection. However, no method has been adapted as a standard clinical diagnostic test for TVVs [15].

Better understanding the diversity of $T$. vaginalis and geographical distribution of various genotypes may improve our knowledge regarding the epidemiology of this infectious agent and contribute to vaccine development efforts. At present, none of the described techniques have been recognized as the "gold standard" for genotyping of T. vaginalis isolates [16-23].

In this study, we opted to sequence the $T$. vaginalis actin gene to better understand the genetic diversity of T. vaginalis. Actin is a ubiquitous well conserved structural protein in all eukaryotic cells [24] and has been used to clarify the molecular phylogeny of protists, plants, animals and fungi [25].

The data produced by sequencing are unambiguous, reproducible and portable, thus offering the advantage that public databases can be constructed. In Kenya, screening for $T$. vaginalis is not routinely done. However, recent studies have indicated that there is high prevalence of $T$. vaginalis among different groups in Kenya [26-29]. Despite this, no typing has been carried out. In this study, we genotyped $T$. vaginalis isolated from pregnant women attending ANC in Kilifi, Kenya.

\section{Methods}

Study design, population and specimens processing

From July through to September 2015, we conducted a cross-sectional study at the antenatal care clinic of Kilifi County Hospital, Kenya. The main aim of that study was to describe the prevalence and predictors of curable sexually transmitted infections (STIs) among pregnant women attending to the antenatal care clinic [29]. Women were eligible if they met the following criteria: age 18-45 years, gestation $\geq 14$ weeks, resident of the Kilifi Health and Demographic Surveillance area, willingness to undergo free STI and bacterial vaginosis screening procedures, and able and willing to give written informed consent [29]. The current study presents a secondary objective of the above-mentioned study, namely to perform typing of $T$. vaginalis clinical isolates from this study population.
A total of 349 pregnant women were included in the study. A nurse collected vaginal secretions from the vaginal introitus using a sterile cotton swab. The vaginal swab was inoculated at the clinic in the upper-chamber of an InPouch system (BioMed Diagnostics, White City, Oregon, USA). The inoculated InPouch was transferred to the laboratory within $15 \mathrm{~min}$ for direct microscopy of the upper chamber, after which it was merged with the lower chamber and incubated at $37 \pm 1{ }^{\circ} \mathrm{C}$ under aerobic conditions. Daily microscopic observation of the InPouch system was performed and media with motile trichomonads within 5 days of culture were considered positive for $T$. vaginalis. Two $\mathrm{ml}$ of the contents of each InPouch system positive for $T$. vaginalis were transferred into a $2.0 \mathrm{ml}$ Eppendorf tube and stored at $-80{ }^{\circ} \mathrm{C}$ until shipment to the Laboratory of Bacteriology Research (Ghent University, Belgium) using shipping boxes filled with dry ice $\left(-78.5^{\circ} \mathrm{C}\right)$. The samples were stored at $-80^{\circ} \mathrm{C}$ until molecular analysis was performed.

Women found to be positive for T. vaginalis using direct microscopy, i.e. microscopy of the upper chamber, were treated on the same day, while women who were negative for $T$. vaginalis using direct microscopy but positive on culture were contacted to return to the clinic for treatment immediately after the culture turned positive. Partners of women treated for $T$. vaginalis infection received presumptive treatment.

\section{Nucleic acid extraction}

Frozen cultures were first thawed at room temperature for $30 \mathrm{~min}$, after which the tubes were vortexed for $30 \mathrm{~s}$ to ensure that a homogeneous mix was achieved before starting the nucleic acid extraction. Total nucleic acid extraction was performed using the NucliSENS ${ }^{\circ}$ easyMAG ${ }^{\circ}$ (bioMérieux, Marcy l'Etoile, France) according to the manufacturer's instructions (generic protocol 2.0.1).

\section{Actin gene PCR}

The actin gene was amplified using the outer primers previously used in a nested polymerase chain reaction (PCR), i.e. primers Tv8S (5'-TCT GGA ATG GCT GAA GAA GAC G-3') and Tv9R (5'-CAG GGT ACA TCG TAT TGG TC-3') [20], with the following thermocycling conditions: $5 \mathrm{~min}$ at $95{ }^{\circ} \mathrm{C}, 40$ cycles of $30 \mathrm{~s}$ at $95{ }^{\circ} \mathrm{C}, 30 \mathrm{~s}$ at $55{ }^{\circ} \mathrm{C}$ and $3 \mathrm{~min}$ at $72{ }^{\circ} \mathrm{C}$, followed by $7 \mathrm{~min}$ at $72{ }^{\circ} \mathrm{C}$. This was performed on the ABI Veriti thermocycler platform (ThermoFisher Scientific, Waltham, Massachusetts, USA).

\section{Gel electrophoresis}

PCR amplification products were visualized under UV light after electrophoresis on $1 \%$ agarose gels in Tris-acetateEDTA buffer $\mathrm{pH} 8.5(30 \mathrm{~min}$ at $10 \mathrm{~V} / \mathrm{cm})$ and staining with ethidium bromide ( $0.5 \mathrm{mg} /$ l; Sigma, Bornem, Belgium). The 
size of the amplified products was assessed by comparison with a commercial weight marker, Smart Ladder (Eurogentec, Liege, Belgium).

\section{Sequencing}

Amplicons $(20 \mu \mathrm{l})$ were sent for sequencing to GATC Biotech (Constance, Germany), using the Sanger sequencing technique. Sequencing was performed bi-directionally using the same primers used in PCR amplification of the actin gene.

\section{Genotyping of $T$. vaginalis}

Trichomonas vaginalis actin sequences were edited using Chromas Lite 2.01 (http://technelysium.com.au/wp/). Furthermore, we identified the $T$. vaginalis actin genotypes amongst our isolates by means of in silico RFLP-analysis Webcutter version 2.0; http://rna.lundberg.gu.se/cutter2/ with the three restriction enzymes (HindII, MseI and RsaI) used by Crucitti et al. [20]. The in silico analysis was done on our clinical isolates and on retrieved sequences representing the genotypes that have been proposed. To identify if there were additional $T$. vaginalis actin genotypes not captured by the previous proposed scheme, in silico RFLP was performed on actin sequences retrieved from the GenBank whose actin genotype is yet to be documented. The sequences were of at least $1100 \mathrm{bp}$ in length (Additional file 1: Table S1).

To compare results obtained in the RFLP analysis, and to determine the genetic variation among the identified genotypes, we performed phylogenetic analysis of the sequences. Sequences obtained in our study were aligned using MEGA software and compared with analogous sequences representative of known $T$. vaginalis actin genotypes identified in from our isolates.

Evolutionary distances were calculated by Kimura's two-parameter model (Kimura, 1980) and a phylogenetic tree was generated using the Maximum Likelihood method using the MEGA software (version 7.0) [30]. Finally, confidence levels were estimated using bootstrap resampling on 1000 randomly selected pseudoreplicates.

\section{Detection of Trichomonas vaginalis viruses}

Synthesis of cDNA was performed on the nucleic acid extract using the RevertAid First Strand cDNA Synthesis Kit (ThermoFisher Scientific, Gent, Belgium). The cDNA was used to amplify the four known TVVs by means of previously described type specific primers: TVV1F2875 (5'ATT AGC GGT GTT TGT GAT GCA-3') and TVV1R3443 (5' -CTA TCT TGC CAT CCT GAC TC-3'), TVV2F1401 (5'-ATT AGC GGT GTT TGT GAT GCA$\left.3^{\prime}\right)$ and TVV2R1953b (5'-GGT TCG TGG AAG CGG TTG ATG A-3'), TVV3F1474 (5' -CTA CCA AGA AGG AGG CTT GA-3') and TVV3R2025b (5'-GGT TCG TGG AAG CGG TTG ATG A-3'), and TVV4F1338 (5' - ATG
CCA GTT GCT TTC CG-3') and TVV4R1834 (5'-TTC CCC AAT AGT TAT CAG-3') [10]. The amplification conditions were: $5 \mathrm{~min}$ at $95^{\circ} \mathrm{C}, 40$ cycles of $30 \mathrm{~s}$ at $95^{\circ} \mathrm{C}, 30 \mathrm{~s}$ at $50{ }^{\circ} \mathrm{C}$ and $45 \mathrm{~s}$ at $72{ }^{\circ} \mathrm{C}$, followed by $7 \mathrm{~min}$ at $72{ }^{\circ} \mathrm{C}$. The PCR products were visualized by electrophoresis as described above.

\section{Statistical analysis}

The socio-demographic and clinical data of the participants were entered in the REDCapTM electronic data capture tool, version 6.5.0 (Vanderbilt University, Nashville, Tennessee). Prevalence of $T$. vaginalis was expressed as a percentage with exact $95 \%$ binomial confidence intervals (CIs). Univariable logistic regression was used to determine associations of $T$. vaginalis presence with socio-demographic data, hygienic data, sexual behavior, and vaginal signs \& symptoms. Variables significant at $P \leq 0.1$ in bivariable analysis were entered into a multivariable model to identify independent associations. Crude odds ratios (COR) and adjusted odds ratios (AOR) were calculated. These statistical analyses were done using STATA, version 13.1 (Stata-Corp, College Station, Texas).

\section{Results}

\section{Characteristics of the study population}

The median age and gestation age including the interquartile range (IQR) for the participants was 27 (22-31) years and 25 (20-30) weeks, respectively. The majority of the participants were married (93.6\%) and Christian (72.3\%). Approximately a quarter of the participants had received secondary school education and above. The median age and IQR of sexual debut was 18.6 (16-20) years, although $17.4 \%$ of the participants were not sure or did not respond to this question. Seventy-three percent of the participants had given birth before and the number of children ranged between 1 and 10. Sixtyfive percent of the participants had previously experienced signs/symptoms associated with reproductive tract infection and about one third had ever received syndromic treatment for genital signs or symptoms of infection. The socio-demographic characteristics of the participants are summarized in Table 1.

\section{Prevalence, clinical signs and symptoms}

A total of $23 / 349$ (6.6\%, 95\% CI: 4.2-9.7) women were culture-positive for $T$. vaginalis, and $34.8 \%$ of these cases were positive by direct microscopy prior to further incubation. Based on symptoms routinely used in syndromic management of STIs (i.e. genital ulcer, lower abdominal pain or abnormal vaginal discharge), $43.5 \%$ of the 23 women with $T$. vaginalis infection were asymptomatic. The most commonly self-reported symptoms amongst all participants included vaginal discharge 
Table 1 Univariable and multivariable analysis of characteristics of pregnant women with $T$. vaginalis attending antenatal care clinic at Kilifi County Hospital, Kenya

\begin{tabular}{llll}
\hline Variable $N=349$ & $\begin{array}{l}\text { Percentage with } \\
\text { T. vaginalis }\end{array}$ & $\begin{array}{l}\text { Crude OR } \\
(95 \% \mathrm{Cl})\end{array}$ & P-value \\
\hline Demographic characteristics & & &
\end{tabular}

Age group (years)

$\begin{array}{lllll}18-24 & 132 & 6.8 & 1.1(0.4-2.5) & 0.894 \\ \geq 25 & 217 & 6.5 & & \end{array}$

Religion

$\begin{array}{lll}\text { Christian } & 248 & 5.7 \\ \text { Muslim } & 54 & 5.7 \\ \text { Other/None } & 47 & 12.8\end{array}$

Education

$\begin{array}{lll}\text { None } & 63 & 7.9 \\ \text { Primary } & 200 & 7.0 \\ \text { Secondary/Tertiary } & 86 & 4.7\end{array}$

Marital status

$\begin{array}{lll}\text { Single } & 25 & 4.0 \\ \text { Married } & 224 & 6.8\end{array}$

Residency

Living with partner $\quad 255 \quad 5.5$

Not living with a $\quad 94 \quad 96$

partner

Employment status

Employed/self- $\quad 199 \quad 5.0$

employed

Unemployed $\quad 150 \quad 8.7$

Parity

$\begin{array}{lll}0 & 94 & 6.4 \\ 1-2 & 133 & 7.5 \\ 3+ & 122 & 5.7\end{array}$

Gestational age (weeks) ${ }^{c}$

$\begin{array}{lll}14-25 & 183 & 5.5 \\ \geq 26 & 165 & 7.9\end{array}$

Hygiene characteristics

Toilet type

$\begin{array}{lll}\text { Flushing toilet } & 117 & 7.7 \\ \text { Pit latrine } & 197 & 5.1 \\ \text { Bush/Other } & 35 & 11.4\end{array}$

Mode of cleaning after visiting the toilet

Tissue paper/Other $\quad 106 \quad 2.8$

solid materials

Water $\quad 243 \quad 8.2$

Behavioral characteristics

Sexual debut age (years)

$\begin{array}{lll}\leq 17 & 106 & 8.5 \\ \geq 18 & 183 & 4.9 \\ \begin{array}{l}\text { Do not know/No } \\ \text { response }\end{array} & 60 & 6.7\end{array}$

$$
1.0(0.3-3.5) \quad 0.979
$$$$
2.4(0.9-6.7) \quad 0.083^{\mathrm{a}}
$$

$0.9(0.3-2.5) \quad 0.802$

$0.6(0.1-2.1) \quad 0.411$

$1.7(0.2-13.5) \quad 0.593$

$1.8(0.8-4.4) \quad 0.178$

$$
\text { ( }
$$$$
\text { (1) }
$$

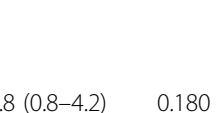

$1.1(0.3-3.5) \quad 0.843$

$1.3(0.5-3.6) \quad 0.570$

$1.5(0.6-3.4) \quad 0.382$

$$
0.6(0.3-1.6) \quad 0.350
$$$$
1.5(0.4-5.4) \quad 0.491
$$

Table 1 Univariable and multivariable analysis of characteristics

\begin{tabular}{|c|c|c|c|c|}
\hline Variable & $N=349$ & $\begin{array}{l}\text { Percentage with } \\
\text { T. vaginalis }\end{array}$ & $\begin{array}{l}\text { Crude OR } \\
(95 \% \mathrm{Cl})\end{array}$ & $P$-value \\
\hline \multicolumn{5}{|c|}{ Number of lifetime sex partners ${ }^{c}$} \\
\hline 1 & 158 & 3.8 & & \\
\hline $2+$ & 189 & 9.0 & $2.5(1.0-6.5)$ & $0.060^{\mathrm{a}}$ \\
\hline \multicolumn{5}{|c|}{ Polygamous partner } \\
\hline No & 303 & 6.9 & $1.6(0.4-7.2)$ & 0.515 \\
\hline Yes & 46 & 4.4 & & \\
\hline \multicolumn{5}{|c|}{ Alcohol consumption ever } \\
\hline No & 262 & 6.5 & $0.9(0.4-2.5)$ & 0.894 \\
\hline Yes & 87 & 6.9 & & \\
\hline \multicolumn{5}{|l|}{ Tobacco use } \\
\hline No & 332 & 6.6 & $1.1(0.1-8.9)$ & 0.904 \\
\hline Yes & 17 & 5.9 & & \\
\hline \multicolumn{5}{|c|}{ Other drugs/substance use ever } \\
\hline No & 332 & 6.6 & $1.1(0.1-8.9)$ & 0.904 \\
\hline Yes & 17 & 5.9 & & \\
\hline \multicolumn{5}{|c|}{ Sexually transmitted infections/reproductive tract infections } \\
\hline \multicolumn{5}{|l|}{ HIV } \\
\hline Negative & 324 & 6.2 & & \\
\hline Positive & 25 & 12.0 & $2.1(0.6-7.5)$ & 0.268 \\
\hline \multicolumn{5}{|c|}{ Bacterial vaginosis $^{d}$} \\
\hline Negative & 293 & 6.5 & & \\
\hline Positive & 53 & 7.6 & $1.1(0.4-3.6)$ & 0.775 \\
\hline \multicolumn{5}{|c|}{ Clinical signs and symptoms of STI } \\
\hline \multicolumn{5}{|c|}{ Previous history of vaginal discharge } \\
\hline No & 122 & 5.6 & & \\
\hline Yes & 227 & 7.1 & $1.2(0.5-3.1)$ & 0.638 \\
\hline
\end{tabular}
of pregnant women with $T$. vaginalis attending antenatal care clinic at Kilifi County Hospital, Kenya (Continued)

Previous syndromic treatment of genital infection

$\begin{array}{lllll}\text { No } & 229 & 6.6 & & \\ \text { Yes } & 120 & 6.7 & 1.0(0.4-2.5) & 0.967\end{array}$

Current vaginal discharge (self-reported) ${ }^{c}$

\begin{tabular}{|c|c|c|c|c|}
\hline No & 271 & 5.9 & & \\
\hline Yes & 77 & 9.1 & $1.6(0.6-4.0)$ & 0.324 \\
\hline \multicolumn{5}{|c|}{ Dysuria $^{c}$} \\
\hline No & 263 & 6.1 & & \\
\hline Yes & 85 & 8.2 & $1.4(0.5-3.5)$ & 0.489 \\
\hline \multicolumn{5}{|c|}{ Dyspareunia $^{c}$} \\
\hline No & 245 & 4.9 & & \\
\hline Yes & 103 & 10.7 & $2.3(1.0-5.4)$ & 0.053 \\
\hline \multicolumn{5}{|c|}{ Vaginal itching ${ }^{c}$} \\
\hline No & 231 & 6.5 & & \\
\hline Yes & 117 & 6.8 & $1.1(0.4-2.6)$ & 0.903 \\
\hline
\end{tabular}

$\begin{array}{lllll}\text { No } & 96 & 3.1 & & \\ \text { Yes } & 252 & 7.9 & 2.7(0.8-9.2) & 0.119\end{array}$

Abnormal vaginal discharge foul smell/color (observed) ${ }^{c}$ 
Table 1 Univariable and multivariable analysis of characteristics of pregnant women with $T$. vaginalis attending antenatal care clinic at Kilifi County Hospital, Kenya (Continued)

\begin{tabular}{|c|c|c|c|c|}
\hline Variable & $N=349$ & $\begin{array}{l}\text { Percentage with } \\
\text { T. vaginalis }\end{array}$ & $\begin{array}{l}\text { Crude OR } \\
(95 \% \mathrm{Cl})\end{array}$ & $P$-value \\
\hline \multicolumn{5}{|c|}{ Lower abdominal pain $^{c}$} \\
\hline No & 169 & 8.3 & & \\
\hline Yes & 179 & 5.0 & $0.6(0.2-1.4)$ & 0.226 \\
\hline \multicolumn{5}{|c|}{ Genital warts $^{c}$} \\
\hline No & 341 & 6.2 & & \\
\hline Yes & 7 & 28.6 & $6.1(1.1-33.3)$ & $0.037^{\mathrm{a}}$ \\
\hline \multicolumn{5}{|c|}{ Genital ulcer (observed) ${ }^{c}$} \\
\hline No & 338 & 5.6 & & \\
\hline Yes & 10 & 40.0 & $11.2(2.9-43.1)$ & $<0.001^{b}$ \\
\hline \multicolumn{5}{|c|}{ Vaginitis $^{c}$} \\
\hline No & 334 & 6.6 & & \\
\hline Yes & 14 & 7.1 & $1.1(0.1-8.7)$ & 0.935 \\
\hline \multicolumn{5}{|c|}{ Symptomatic $^{c}$} \\
\hline No & 145 & 6.9 & & \\
\hline Yes & 203 & 6.4 & $0.9(0.4-2.2)$ & 0.855 \\
\hline
\end{tabular}

${ }^{\mathrm{a} S i g n i f i c a n t ~ i n ~ u n i v a r i a b l e ~ a n a l y s i s ~}$

${ }^{\mathrm{b}}$ Significant on multivariable association; symptomatic (any or a combination of the three symptoms, i.e. genital ulcer, lower abdominal pain or abnormal vaginal discharge)

'Missing data/some participants did not respond to this question(s)

${ }^{\mathrm{d}}$ Bacterial vaginosis results for three participants were not available due to poor slides

(72.4\%). However, during collection of specimens by the study nurse, only $22.1 \%$ of the participants had an abnormal discharge (defined as excess discharge/foul smelling discharge/colored discharge) upon examination. A total of $51.4 \%$ of the women reported having lower abdominal pain, genital ulcers were observed in $2.9 \%$ of the women. Dyspareunia, genital warts and genital ulcers were the only clinical signs or symptoms significantly associated with $T$. vaginalis infection (Chi-square test: $\chi^{2}=3.93, d f=1, P<0.048$; $\chi^{2}=5.58, d f=1, P<0.018$; and $\chi^{2}=18.60, d f=1, P<0.05$, respectively).

\section{Predictors of $T$. vaginalis infection}

Univariable analysis indicated that $T$. vaginalis infection was more common among participants who were traditionalist or reported having no religion compared to participants who were Christians or Muslims, used water to clean themselves after visiting the toilet compared to those who used tissue paper or other solid materials, reported having $\geq 2$ lifetime sexual partners, reported dyspareunia, had genital warts, and/or had a genital ulcer (Table 1). In multivariable analysis, the only independent predictor associated with $T$. vaginalis was having a genital ulcer (AOR = 7.6, 95\% CI: 1.4-42.3).

\section{Genotyping analysis}

The actin gene target could be amplified from 21 of the 23 T. vaginalis isolates. All 21 amplicons had the expected length of approximately $1100 \mathrm{bp}$. The two remaining isolates could only be amplified by a higher primer concentration of $0.5 \mu \mathrm{M}$, instead of $0.3 \mu \mathrm{M}$. However, one of these clinical isolates did not yield an interpretable sequence and thus only sequences from 22 clinical isolates were utilized in the typing. Five different actin types (E, G, I, N and P) were identified according to the position and the number of cleavage sites, following the scheme proposed by Crucitti et al. [20] (Table 2). The most prevalent actin genotype was E, representing $50.0 \%$ of the isolates. The other genotypes were, in order of descending frequency, N (27.3\%), G (13.6\%) and I and P (each 4.5\%).

Multiple sequence analysis to compare polymorphic sites found on our actin sequences, and those retrieved from the GenBank, revealed a total of 33 single nucleotide differences in the open reading frame of the actin gene. Three of these single nucleotide polymorphisms were exclusively found in actin sequences from our study (Additional file 2). The nucleotide sequences obtained of the actin gene for all the 22 isolates were submitted in GenBank under accession numbers: (MF350322-MF350343). The phylogenetic analysis (Fig. 1) showed that actin genotype E clustered with a bootstrap value of 99. Lower bootstrap values were observed for actin genotypes N, G, I and P.

\section{Prevalence of $T$. vaginalis viruses}

TVVs were present in 43.5\% (95\% CI: 23.2-65.5) (10/23) of $T$. vaginalis isolates. Trichomonas vaginalis virus type 1 (TVV1) was the most prevalent (39.1\%), followed by

Table 2 Number and position of restriction sites using Hindll, Msel and Rsal restriction enzymes

\begin{tabular}{|c|c|c|c|c|c|c|c|c|c|c|c|c|}
\hline \multirow[t]{2}{*}{ Genotype } & \multirow{2}{*}{$\begin{array}{l}\text { No. of } \\
\text { isolates }\end{array}$} & \multicolumn{3}{|c|}{ Hindll } & \multicolumn{3}{|l|}{ Msel } & \multicolumn{5}{|l|}{ Rsal } \\
\hline & & 213 & 273 & 699 & 185 & 314 & 518 & 103 & 190 & 426 & 878 & 994 \\
\hline$E$ & 11 & $x$ & $\times$ & & & $\times$ & $\times$ & $\times$ & $\times$ & $\times$ & & $\times$ \\
\hline G & 3 & $\times$ & $\times$ & $x$ & & & $\times$ & & $\times$ & $\times$ & & $\times$ \\
\hline I & 1 & $\times$ & $\times$ & $\times$ & & & $\times$ & & $\times$ & $x$ & $\times$ & $\times$ \\
\hline $\mathrm{N}$ & 6 & $x$ & $\times$ & $\times$ & $x$ & & $\times$ & $x$ & $\times$ & $x$ & & $\times$ \\
\hline$P$ & 1 & $\times$ & $\times$ & $\times$ & & & $\times$ & $\times$ & $\times$ & $x$ & $\times$ & $\times$ \\
\hline
\end{tabular}

$x$ indicates the presence of a restriction cut site 


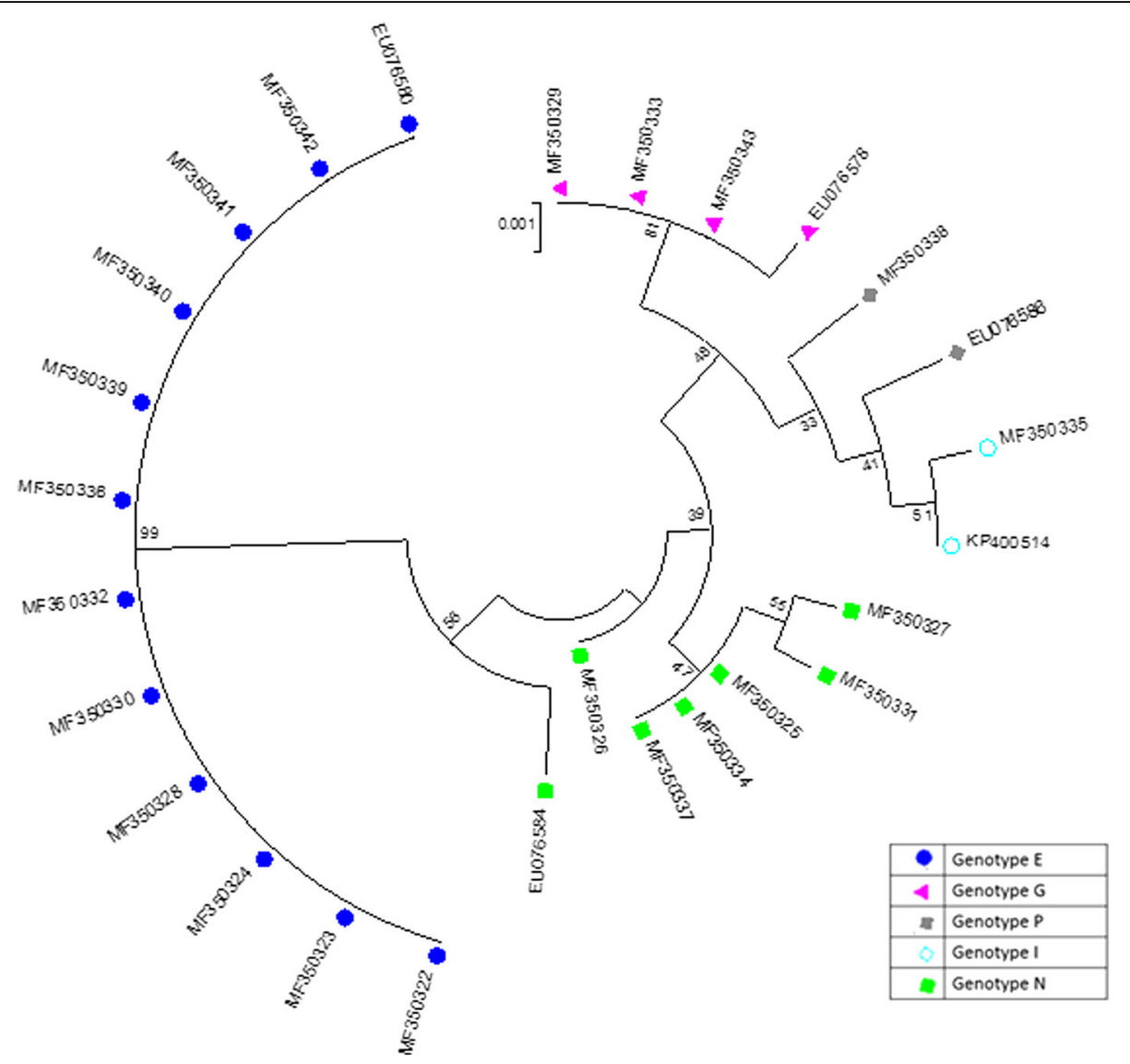

Fig. 1 Phylogenetic tree for actin gene nuclotide sequences of T. vaginalis. The tree was generated using Maximum Likelihood method. Bootstrap test for 1000 replicates. Sequences from Kilifi isolates $(n=22)$ have accession numbers with the prefix "MF", all other sequences were retreived from GenBank and are representative of the five actin genotypes. Scale-bar: 0.001 (1 substitution per 1000 nucleotides)

TVV2 (26.1\%), TVV3 (17.4\%) and TVV4 (13.0\%). Nine out of $10 \mathrm{~T}$. vaginalis isolates with TVVs harbored more than one type of TVV (Table 3). TVV1 was present in all virus-positive T. vaginalis isolates but one (TV207). All 11 genotype $\mathrm{E}$ isolates were virus-negative.

Finally, the distribution of symptomatic and asymptomatic cases was not linked to any particular T. vaginalis actin genotype. Similarly, presence or absence of TVVs did not appear to have an influence as to whether a patient was symptomatic or asymptomatic.

\section{Discussion}

To our knowledge, this is the first study determining $T$. vaginalis genotypes and co-occurrence of $T$. vaginalis viruses in Kenya. We sequenced the actin gene for 22 isolates and identified five types of $T$. vaginalis by in silico RFLPanalysis of the amplified actin gene. We found notable genetic diversity by full actin gene sequence analysis among $T$. vaginalis isolates in Kilifi, as well as those retrieved from GenBank. Prevalence of T. vaginalis in this study $(6.6 \%$ in 349 pregnant women) was high but, however, fell short of the prevalence of $T$. vaginalis among women aged 15-
49 years in the World Health Organization Africa region in 2012, which was estimated to be $11.5 \%$ (95\% CI: 9.0-14.6) [1]. This is suggestive of lower rates of $T$. vaginalis among the general population of women in Kilifi, Kenya compared to other African countries [31].

Although $T$. vaginalis does not traditionally present with genital ulcers [32], multivariable analysis showed that genital ulcers were the only predictor of an infection with T. vaginalis in our study. Ulcers could not be due to syphilis, which was not diagnosed in any of the women with $T$. vaginalis, but we did not test for the Herpes simplex virus, which is also associated with genital ulcers. The association of genital ulcer with $T$. vaginalis is not unique to our study as it has been reported amongst female sex workers in China [33].

Nucleotide sequence analysis of actin sequences showed 33 polymorphic sites, three of which caused amino acid substitution. Two of these amino acid substitutions have been previously reported to occur in genotypes G, N, I and $\mathrm{P}$, in which nucleotide 371 substituted alanine for valine, and nucleotide 904 substituted lysine for glutamine [20, 34]. A unique polymorphism leading to an amino acid 
Table 3 Genotypes of Trichomonas vaginalis and carriage of T. vaginalis viruses, in relation to symptoms among $23 T$. vaginalis isolates in Kilifi, Kenya

\begin{tabular}{|c|c|c|c|c|c|c|}
\hline Sample ID & TW1 & TW2 & TW3 & TW4 & Genotype & Symptomatic $^{\mathrm{a}}$ \\
\hline TV279 & + & - & + & - & $*$ & + \\
\hline TV022 & - & - & - & - & E & + \\
\hline TV042 & - & - & - & - & E & + \\
\hline TV050 & - & - & - & - & $E$ & - \\
\hline TV066 & - & - & - & - & E & + \\
\hline TV075 & - & - & - & - & E & + \\
\hline TV176 & - & - & - & - & E & - \\
\hline TV188 & - & - & - & - & E & - \\
\hline TV203 & - & - & - & - & E & + \\
\hline TV224 & - & - & - & - & E & - \\
\hline TV299 & - & - & - & - & E & + \\
\hline TV323 & - & - & - & - & E & - \\
\hline TV185 & + & - & + & + & G & - \\
\hline TV207 & - & + & - & - & G & + \\
\hline TV238 & + & + & + & - & G & + \\
\hline TV307 & + & + & - & - & 1 & - \\
\hline TV116 & + & + & - & - & $\mathrm{N}$ & - \\
\hline TV131 & + & + & - & - & $\mathrm{N}$ & + \\
\hline TV156 & + & - & - & + & $N$ & - \\
\hline TV190 & + & + & + & - & $\mathrm{N}$ & + \\
\hline TV210 & - & - & - & - & $\mathrm{N}$ & + \\
\hline TV234 & + & - & - & + & $\mathrm{N}$ & - \\
\hline TV140 & - & - & - & - & $P$ & + \\
\hline
\end{tabular}

Abbreviations: TVV1 Trichomonas vaginalis virus type 1, TVV2 T. vaginalis virus type 2, TVV3 $T$. vaginalis virus type 3, TVV4 $T$. vaginalis virus type 4 Code: *Not typed; + present; - absent

a Symptomatic: any or a combination of the three symptoms, i.e. genital ulcer, lower abdominal pain and/or abnormal vaginal discharge

substitution, in which nucleotide 892 substituted threonine for serine, was observed to be exclusively present on a GenBank sequence (accession number XM_001301892). As such, in silico genotyping of isolates provides an opportunity to distinguish closely related isolates based on these polymorphic sites and to further identify such polymorphic sites.

Our phylogenetic analysis confirms RFLP as a good typing method, as the results from this method were in agreement with phylogenetic analysis. Phylogenetic analysis and detection of carriage of TVVs, revealed that none of the isolates of the most prevalent actin genotype E harbored a TVV. Furthermore, phylogenetic analysis indicated that genotype $\mathrm{E}$ formed a distinct phylogenetic lineage, suggesting clonal stability of this genotype [35].

The high prevalence $(43.5 \%)$ of TVVs found in this study is comparable to a prevalence of $55 \%$ (95\% CI: 38.4-70.7) among Cuban isolates [36]. Two recent studies have reported lower carriage of TVV, 18.7\% (95\% CI: 11.5-28.0) in the Philippines [37] and 17.3\% (95\% CI: 7.8-31.4) among Iranian isolates [38], although the latter study only determined the presence of TVV1. However, higher prevalence rates of TVV have been reported as well, $81.9 \%$ (95\% CI: 71.1-90.0) in South Africa [39], and 75.0\% (95\% CI: 55.1-89.3) in Baltimore City, Maryland [40]. The presence of TVV, in addition to metronidazole susceptibility, has been found to differ significantly between $T$. vaginalis isolates genotyped by a panel of 21 microsatellites and six single-copy genes of $T$. vaginalis, which classifies $T$. vaginalis into two types: type 1 and type 2 [23]. Type 2 is characteristically free of TVV and resistant to metronidazole [23]. Metronidazole susceptibility in relation to actin genotypes is yet to be determined.

Fifty-seven percent of isolates in our study did not harbor TVV, suggesting that they might be of type 2 . Our study might have been biased towards type 2; $63.6 \%$ were recovered from patients who were diagnosed by culture, after direct microscopy had been determined to be negative, suggesting that the parasite load in the patient was low. Conrad et al. [23] observed that type 1 parasites are often diagnosed by direct microscopy and suggested that this may be indicative of higher parasite load in type 1 which harbor TVVs. Additional studies, sampling a more diverse population and other regions in Kenya, are needed to confirm the population type and distribution of $T$. vaginalis in the country.

A total of $22 \mathrm{TVVs}$ were identified in $10 \mathrm{~T}$. vaginalis cultures, with multiple TVVs detected in nine cultures (Table 2). The higher prevalence of $T$. vaginalis cultures with either TVV1 or TVV2 than with TVV3 or TVV4 is consistent with previous reports $[10,37]$. In these publications, concurrent TVV infection, with at least two or 3 TVVs, was recorded in six and three T. vaginalis sample cultures, respectively. Although we identified single actin genotypes in all $T$. vaginalis cultures, which is indicative for the presence of only $1 T$. vaginalis strain per culture, we cannot rule out that the presence of the multiple TVVs may be the result of a mixture of $T$. vaginalis strains, each infected with a different TVV. Therefore, our data does not necessarily indicate concurrent infection of TVVs in a single TV strain. The lytic cycle of TVVs is yet to be described, and attempts to infect uninfected isolates have been unsuccessful [41]. Therefore, it is plausible that the virus may solely be acquired through vertical transmission, making its presence an important genetic marker [42].

Fifty-six percent of women with $T$. vaginalis infection in our study were symptomatic and the symptoms occurred independently of the presence of TVV in the protozoon. In vitro studies have shown that TVVs are sensed by the 
human epithelial cells via Toll-like receptor 3, triggering Interferon Regulating Factor - 3, interferon type I and pro-inflammatory cascades previously implicated in preterm birth and HIV-1 susceptibility [12]. While treatment with metronidazole generally eliminates $T$. vaginalis, this may aggravate $T$. vaginalis-associated inflammation caused by the release of TVV by stressed or dying parasites [12]. Additionally, TVVs upregulate levels of phenotypically variable immunogen mRNA P270 of T. vaginalis [13], while also playing a role in $T$. vaginalis protein composition and its growth kinetics [14].

\section{Conclusion}

Our study was limited by the small number of isolates, which rendered it difficult to investigate the implication of TVV carriage on clinical signs and symptoms. Despite the low number of $T$. vaginalis isolates, the presence of all four types of TVVs in our isolates, in addition to the five actin genotypes, demonstrates there is notable genetic diversity of $T$. vaginalis isolated from pregnant women in Kilifi, Kenya. Isolates of the most prevalent actin genotype E lacked TVVs; further studies with higher number of strains should be conducted in order to corroborate these results. The actin gene should be considered as a potential genetic marker for molecular epidemiology and genotypic traits of T. vaginalis.

\section{Additional files}

Additional file 1: Table S1. Genotype, number and position of restriction sites using Hindll, Msel and Rsal restriction enzymes for actin sequences retrieved from GenBank. (DOCX $15 \mathrm{~kb}$ )

Additional file 2: Figure S1. Alignment of the T. vaginalis actin gene nucleotide sequences retrieved from GenBank and those of from the clinical T. vaginalis isolates of the present study. (PDF $1746 \mathrm{~kb}$ )

\section{Abbreviations}

RFLP: Restriction fragment length polymorphism; TW: Trichomonas vaginalis viruses

\section{Acknowledgments}

We would like to thank the study participants and a special thanks to all nurses at the ANC clinic of the Kilifi County Hospital. This manuscript was submitted for publication with permission from the Director of the Kenya Medical Research Institute (KEMRI).

\section{Funding}

This research has been supported by a PhD Scholarship for SCM from the Belgian Development Cooperation through VLIR-UOS. The Kenya Medical Research Institute-Wellcome Trust Research Programme (KWTRP) at the Centre for Geographical Medicine Research-Kilifi is supported by core funding from the Wellcome Trust (\#077092). The funders had no role in the in the design of the study and collection, analysis, and interpretation of data and in writing the manuscript. The views expressed here are those of the authors and do not necessarily represent the views of the Belgian Development Cooperation, or the Wellcome Trust.

\section{Availability of data and materials}

The datasets supporting the conclusions of this article are included within the article and its additional files. In addition, sequence generated in the study are available on GenBank under the accession numbers MF350322-MF350343.

\section{Authors' contributions}

SCM, PC, EJS and MV designed the study. SCM supervised the field data collections. SCM and PC conducted laboratory analysis and contributed to the interpretation of data. SCM wrote the initial manuscript draft, PC, EJS, TC and MV contributed to the interpretation of data and critically reviewed the manuscript. All authors read and approved the final manuscript.

\section{Ethics approval and consent to participate}

The study was approved by the Kenya Medical Research Institute (KEMRI) Scientific and Ethics Review Unit (\#3022). All participants provided written informed consent for study participation.

Consent for publication

Not applicable.

\section{Competing interests}

The authors declare that they have no competing interests.

\section{Publisher's Note}

Springer Nature remains neutral with regard to jurisdictional claims in published maps and institutional affiliations.

\section{Author details}

${ }^{1}$ Centre for Geographic Medicine Research - Coast, Kenya Medical Research Institute (KEMRI), P.O. Box 230-80108, Kilifi, Kenya. ' Laboratory Bacteriology Research, Faculty of Medicine and Health Sciences, Ghent University, De Pintelaan, 1859000 Ghent, Belgium. ${ }^{3}$ Department of Biological Sciences, Faculty of Pure and Applied Sciences, Pwani University, P.O. BOX 195-80108, Kilifi, Kenya. ${ }^{4} \mathrm{HIV} / \mathrm{STI}$ Reference Laboratory, Department of Clinical Sciences, Institute of Tropical Medicine, Nationalestraat 155, 2000 Antwerpen, Belgium.

Received: 6 July 2017 Accepted: 23 October 2017

Published online: 30 October 2017

References

1. Newman L, Rowley J, Vander Hoorn S, Wijesooriya NS, Unemo M, Low N, et al. Global estimates of the prevalence and incidence of four curable sexually transmitted infections in 2012 based on systematic review and global reporting. PLoS One. 2015:10:e0143304.

2. Petrin D, Delgaty K, Bhatt R, Garber G. Clinical and microbiological aspects of Trichomonas vaginalis. Clin Microbiol Rev. 1998;11:300-17.

3. Krieger JN. Prostatitis syndromes: pathophysiology, differential diagnosis, and treatment. Sex Transm Dis. 1984;11:100-12.

4. Sangkomkamhang US, Lumbiganon P, Prasertcharoensuk W, Laopaiboon M. Antenatal lower genital tract infection screening and treatment programs for preventing preterm delivery. Cochrane Database Syst Rev. 2015;2:Cd006178.

5. Nakubulwa S, Kaye DK, Bwanga F, Tumwesigye NM, Mirembe FM. Genital infections and risk of premature rupture of membranes in Mulago hospital, Uganda: a case control study. BMC Res Notes. 2015;8:573.

6. Silver BJ, Guy RJ, Kaldor JM, Jamil MS, Rumbold AR. Trichomonas vaginalis as a cause of perinatal morbidity: a systematic review and meta-analysis. Sex Transm Dis. 2014:41:369-76.

7. McClelland RS, Sangare L, Hassan WM, Lavreys L, Mandaliya K, Kiarie J, et al. Infection with Trichomonas vaginalis increases the risk of HIV-1 acquisition. J Infect Dis. 2007;195:698-702

8. Sorvillo F, Kerndt P. Trichomonas vaginalis and amplification of HIV-1 transmission. Lancet. 1998;351:213-4.

9. Carlton JM, Hirt RP, Silva JC, Delcher AL, Schatz M, Zhao Q, et al. Draft genome sequence of the sexually transmitted pathogen Trichomonas vaginalis. Science. 2007;315:207-12.

10. Goodman RP, Freret TS, Kula T, Geller AM, Talkington MWT, Tang-Fernandez $V$, et al. Clinical isolates of Trichomonas vaginalis concurrently infected by strains of up to four trichomonasvirus species (family Totiviridae). J Virol. 2011;85:4258-70.

11. Goodman RP, Ghabrial SA, Fichorova RN, Nibert ML. Trichomonasvirus: a new genus of protozoan viruses in the family Totiviridae. Arch Virol. 2011;156:171-9. 
12. Fichorova RN, Lee Y, Yamamoto HS, Takagi Y, Hayes GR, Goodman RP, et al. Endobiont viruses sensed by the human host beyond conventional antiparasitic therapy. PLoS One. 2012;7:e48418.

13. Khoshnan A, Alderete JF. Trichomonas vaginalis with a double-stranded RNA virus has upregulated levels of phenotypically variable immunogen mRNA. Virology. 1994:68:4035-8.

14. Provenzano D, Khoshnan A, Alderete JF. Involvement of dsRNA virus in the protein composition and growth kinetics of host Trichomonas vaginalis. Arch Virol. 1997;142:939-52.

15. Fichorova R, Fraga J, Rappelli P, Fiori PL. Trichomonas vaginalis infection in symbiosis with Trichomonasvirus and Mycoplasma. Res Microbiol. 2017;10. 1016/j.resmic.2017.03.005

16. Vohra H, Sharma P, Sofi BA, Gupta I, Ganguly NK, Mahajan RC, et al. Correlation of zymodeme patterns, virulence \& drug sensitivity of Trichomonas vaginalis isolates from women. Indian J Med Res. 1991;93:37-9.

17. Torian BE, Connelly RJ, Barnes RC, Kenny GE. Antigenic heterogeneity in the 115,000 mr major surface antigen of Trichomonas vaginalis. PRO. 1988:35:273-80.

18. Upcroft JA, Delgadillo-Correa MG, Dunne RL, Sturm AW, Johnson PJ, Upcroft P. Genotyping Trichomonas vaginalis. Int J Parasitol. 2006;36:821-8.

19. Fraga J, Rojas L, Sariego I, Fernandez-Calienes A. Double-stranded RNA viral infection of Trichomonas vaginalis and correlation with genetic polymorphism of isolates. Exp Parasitol. 2011;127:593-9.

20. Crucitti T, Abdellati S, Van Dyck E, Buve A. Molecular typing of the actin gene of Trichomonas vaginalis isolates by PCR-restriction fragment length polymorphism. Clin Microbiol Infect. 2008;14:844-52.

21. Kaul P, Gupta I, Sehgal R, Malla N. Trichomonas vaginalis: random amplified polymorphic DNA analysis of isolates from symptomatic and asymptomatic women in India. Parasitol Int. 2004;53:255-62.

22. Conrad M, Zubacova Z, Dunn LA, Upcroft J, Sullivan SA, Tachezy J, et al. Microsatellite polymorphism in the sexually transmitted human pathogen Trichomonas vaginalis indicates a genetically diverse parasite. Mol Biochem Parasitol. 2011;175:30-8.

23. Conrad MD, Gorman AW, Schillinger JA, Fiori PL, Arroyo R, Malla N, et al. Extensive genetic diversity, unique population structure and evidence of genetic exchange in the sexually transmitted parasite Trichomonas vaginalis. PLoS Negl Trop Dis. 2012;6:e1573.

24. Kabsch W, Vandekerckhove J. Structure and function of actin. Annu Rev Biophys Biomol Struct. 1992;21:49-76.

25. Drouin G. Moniz de Sa M, Zuker M. The Giardia lamblia actin gene and the phylogeny of eukaryotes. J Mol Evol. 1995;41:841-9.

26. Gomih-Alakija A, Ting J, Mugo N, Kwatampora J, Getman D, Chitwa M, et al. Clinical characteristics associated with Mycoplasma genitalium among female sex workers in Nairobi, Kenya. J Clin Microbiol. 2014;52:3660-6.

27. Unger JA, Matemo D, Pintye J, Drake A, Kinuthia J, McClelland RS, et al. Patient-delivered partner treatment for chlamydia, gonorrhea, and trichomonas infection among pregnant and postpartum women in Kenya. Sex Transm Dis. 2015;42:637-42.

28. Kerubo E, Laserson KF, Otecko N, Odhiambo C, Mason L, Nyothach E, et al. Prevalence of reproductive tract infections and the predictive value of girls' symptom-based reporting: findings from a cross-sectional survey in rural western Kenya. Sex Transm Infect. 2016;92:251-6.

29. Masha SC, Wahome E, Vaneechoutte M, Cools P, Crucitti T, Sanders EJ. High prevalence of curable sexually transmitted infections among pregnant women in a rural county hospital in Kilifi, Kenya. PLoS One. 2017;12:e0175166.

30. Kumar S, Stecher G, Tamura K. MEGA7: molecular evolutionary genetics analysis version 7.0 for bigger datasets. Mol Biol Evol. 2016;33:1870-4.

31. Hokororo A, Kihunrwa A, Hoekstra P, Kalluvya SE, Changalucha JM, Fitzgerald DW, et al. High prevalence of sexually transmitted infections in pregnant adolescent girls in Tanzania: a multi-community cross-sectional study. Sex Transm Infect. 2015;91:473-8.

32. Swygard H, Sena AC, Hobbs MM, Cohen MS. Trichomoniasis: clinical manifestations, diagnosis and management. Sex Transm Infect. 2004;80:91-5.

33. Luo L, Reilly KH, Xu JJ, Wang GX, Ding GW, Wang N, et al. Prevalence and correlates of Trichomonas vaginalis infection among female sex workers in a city in Yunnan Province. China Int J STD AIDS. 2016;27:469-75.

34. Momeni Z, Sadraei J, Kazemi B, Dalimi A. Molecular typing of the actin gene of Trichomonas vaginalis isolates by PCR-RFLP in Iran. Exp Parasitol. 2015;159:259-63.

35. Tibayrenc M, Kjellberg F, Ayala FJ. A clonal theory of parasitic protozoa: the population structures of Entamoeba, Giardia, Leishmania, Naegleria, Plasmodium, Trichomonas, and Trypanosoma and their medical and taxonomical consequences. Proc Natl Acad Sci USA. 1990;87:2414-8.
36. Fraga J, Rojas L, Sariego I, Fernandez-Calienes A. Double-stranded RNA viral infection in Cuban Trichomonas vaginalis isolates. Brazil J Infect Dis. 2005;9:521-4.

37. Rivera WL, Justo CA, Relucio-San Diego MA, Loyola LM. Detection and molecular characterization of double-stranded RNA viruses in Philippine Trichomonas vaginalis isolates. J Microbiol Immunol Infect. 2015;10.1016/j. jmii.2015.07.016.

38. Heidary S, Bandehpour M, Valadkhani Z, Seyyed-Tabaee S, Haghighi A, Abadi A, et al. Double-stranded RNA viral infection in Tehran Trichomonas vaginalis isolates. Iranian J Parasitol. 2013;8:60-4.

39. Weber B, Mapeka TM, Maahlo MA, Hoosen AA. Double stranded RNA virus in south African Trichomonas vaginalis isolates. J Clin Pathol. 2003:56:542-3.

40. Wendel KA, Rompalo AM, Erbelding EJ, Chang TH, Alderete JF. Doublestranded RNA viral infection of Trichomonas vaginalis infecting patients attending a sexually transmitted diseases clinic. J Infect Dis. 2002;186:558-61.

41. Wang AL, Wang CC. The double-stranded RNA in Trichomonas vaginalis may originate from virus-like particles. Proc Natl Acad Sci USA. 1986;83: 7956-60.

42. Malla N, Kaul P, Sehgal R, Gupta I. The presence of dsRNA virus in Trichomonas vaginalis isolates from symptomatic and asymptomatic Indian women and its correlation with in vitro metronidazole sensitivity. Indian J Med Microbiol. 2011;29:152-7.

\section{Submit your next manuscript to BioMed Central and we will help you at every step:}

- We accept pre-submission inquiries

- Our selector tool helps you to find the most relevant journal

- We provide round the clock customer support

- Convenient online submission

- Thorough peer review

- Inclusion in PubMed and all major indexing services

- Maximum visibility for your research

Submit your manuscript at www.biomedcentral.com/submit
) Biomed Central 